\title{
Aspirin and clopidogrel resistance: methodological challenges and opportunities
}

\author{
This article was published in the following Dove Press journal: \\ Vascular Health and Risk Management \\ I March 2010 \\ Number of times this article has been viewed
}

\author{
Armen Yuri Gasparyan \\ Clinical Research Unit, Russell's \\ Hall Hospital, Dudley Group \\ of Hospitals NHS Foundation Trust, \\ West Midlands, UK
}

Correspondence: Armen Yuri Gasparyan Clinical Research Unit, Russell's Hall Hospital, Dudley Group of Hospitals NHS Foundation Trust, Dudley, West Midlands DYI 2HQ, UK Email a.gasparyan@gmail.com

\begin{abstract}
Antiplatelet drug resistance is one of the urgent issues in current cardiovascular medicine. Many platelet function tests have been used to define responsiveness of patients with cardiovascular disease to aspirin and clopidogrel. In most studies, cut-off values of platelet function tests for defining responsiveness to antiplatelets were chosen arbitrarily. Different tests provided wide-ranging figures of the prevalence of aspirin and clopidogrel resistance, suggesting poor correlation between currently available platelet function tests. Measurement of platelet size seems to be a promising approach for monitoring antiplatelet drug therapy. This commentary highlights some limitations of studies on aspirin and clopidogrel resistance in patients undergoing coronary interventions.
\end{abstract}

Keywords: aspirin, clopidogrel, resistance, cardiovascular disease, platelet function tests

Antiplatelet resistance is one of the urgent issues in current cardiovascular medicine. With the wide-spread clinical use of low-dose aspirin, it has become possible to substantially reduce incidence of vascular thrombotic events in patients with cardiovascular and cerebrovascular disease. Antithrombotic Trialists' Collaboration provided robust evidence distinguishing 75 to $150 \mathrm{mg}$ /daily aspirin therapy as an effective means for secondary cardiovascular prevention. ${ }^{1}$ At the same time, it has become clear that a substantial proportion of patients at high risk of cardiovascular events do not benefit from aspirin monotherapy or even aspirin and clopidogrel dual therapy. ${ }^{2}$ In other words, antiplatelets fail to suppress their targets and to prevent cardiovascular events in a cohort of patients owing to several biochemical and clinical factors. The latter study led to emergence of a new phenomenon of 'aspirin and/or clopidogrel resistance' and prompted a search for platelet function tests that could reliably monitor suppression of antiplatelet targets.

Numerous studies using different platelet function tests provided estimates of the prevalence ranging from $5.5 \%$ to $60 \%$ for aspirin resistance ${ }^{2}$ and $16.8 \%$ to $21 \%$ for clopidogrel resistance. ${ }^{3,4}$ Not surprisingly, replacement of aspirin monotherapy with dual (aspirin plus clopidogrel) or even triple antiplatelet therapy (aspirin plus clopidogrel plus dipyridamol or another more potent agent) was suggested. The initial strategy of the replacement, however, became more cautious when more research data on putative mechanisms of the resistance accumulated and research methodology of initial studies analyzed.

It appears that aspirin non-compliance can underlie occurrence of thrombotic complications in a large proportion of patients. At least one-third of patients categorized as having aspirin resistance turned out to be simply those who neglect taking 
aspirin daily. ${ }^{5}$ Other important and perhaps not less frequent mechanical causes of so called aspirin resistance can be co-administration of other non-steroidal anti-inflammatory drugs or intake of less bioavailable enteric-coated aspirin instead of easy dispersible tablets. ${ }^{6}$ Moreover, antiplatelet effects of aspirin are minimal, if not absent, in the case of infections with overproduction of C-reactive protein (CRP). ${ }^{7}$ Similarly, it is unlikely to achieve substantial antithrombotic effects with low-dose aspirin in inflammatory arthritis, diabetes, and in condition associated with surgical stress, where platelet turnout (thrombocytosis), oxidative stress and CRP elevation counteract and outweigh cyclooxygenase-1 (COX-1) dependent effect of aspirin. ${ }^{2}$

In the latest review on aspirin and clopidogrel resistance, Sharma et $\mathrm{al}^{8}$ raised a question of why we still do not monitor platelet function in patients taking antiplatelets, and presented several tests for tailoring antiplatelet therapy and stratifying patients into non-responsive, hyporesponsive, and responsive to aspirin and clopidogrel. The issue has been previously discussed and many drawbacks of each platelet function test have been identified. ${ }^{9}$ As a result, none of the currently available tests, including platelet aggregometry and the Platelet Function Analyzer-100 ${ }^{\mathrm{TM}}$ (PFA-100 ${ }^{\mathrm{TM}}$ ) can be recommended for clinical practice.

Optical aggregometry, a gold standard of platelet function testing, which was used in most studies on aspirin and clopidogrel resistance, requires a relatively large amount of blood, does not take into account interaction of platelets with other cells, and can yield unpredictable results owing to changes of platelet activity markers during blood sampling, storing, separating, and diluting preparing platelet reach plasma, and processing samples.

The PFA- $100^{\mathrm{TM}}$ is a relatively simple test based on blood clotting in shear stress condition. This test, however, is not entirely dependent on platelet function, and measurement of other predictors of thrombosis initiated by shear stress, such as von Willebrand factor, is strongly recommended.

It should be stressed that the VerifyNow ${ }^{\mathrm{TM}}$ is a modified platelet aggregation test, which enables platelet activation during blood sampling and processing to be avoided and specifically assesses the blockade of either arachidonic acid or purinergic pathways in platelets.

Another highly specific test presented is vasodilatorstimulated phosphoprotein (VASP) phosphorylation flow cytometry test, which is used in studies of clopidogrel resistance. However, this and other flow cytometry tests are expensive and should be used only by experienced laboratory personnel.
The most challenging problem in terms of platelet function testing for defining responsiveness to antiplatelets seems to be the lack of correlation between results of the majority of currently available tests. Remarkably, Lordkipanidze et $\mathrm{al}^{10}$ used 6 different tests and obtained varying degrees of the prevalence of aspirin resistance: the lowest (6.7\%) was detected by the VerifyNow point-of-care test and the highest $(59.5 \%)$ by the PFA-100 test. Similarly, poor correlation was reported between 4 different tests in another study on clopidogrel resistance. ${ }^{11}$

There is, however, a possibility of using relatively simple and readily available tests, such as measurement of mean platelet volume (MPV) by automated cell counter, highlighted in a few recent studies on antiplatelet resistance. ${ }^{12-14}$ This test can be viewed as an alternative to many expensive new tests. MPV is a surrogate marker of platelet function and valuable prognostic parameter: the large size of platelets is known to be associated with poor vascular prognosis. MPV values are predetermined by size and activity of platelets newly released from bone marrow and remain stable throughout their life in the circulation. It is, therefore, likely that MPV measurement may be especially useful for monitoring response to antiplatelets suppressing low-grade inflammation and megakaryopoiesis (eg, clopidogrel). Actually, in one small study, aspirin was shown to exert an insignificant effect on MPV. ${ }^{15}$ However, a more recent study using MPV along with VerifyNow tests for defining responsiveness to aspirin and clopidogrel showed strong correlation between these tests, which may indicate the utility of MPV measurement for predicting antiplatelet resistance and related thrombotic events. ${ }^{16}$ After all, the most important factor limiting widespread use of MPV is the risk of platelets swelling in test tubes containing ethylene diamine tetraacetic acid and the distortion of the real picture of platelet activity with delayed processing of samples (after 1-2 hours of blood sampling).

Arbitrary chosen cut-off values of platelet function tests is another big issue in the context of accurately defining (non) responsiveness or resistance to antiplatelets. An appropriate example of the arbitrary and highly controversial definition of aspirin resistance is an approach used in a landmark prospective study on aspirin resistance by Gum et al who detected aspirin resistance in $5.2 \%$ of patients with stable coronary artery disease based on optical platelet aggregation of more than $20 \%$ with $0.5 \mathrm{mg} / \mathrm{mL}$ of arachidonic acid and, surprisingly, more than $70 \%$ with $10 \mu \mathrm{M}$ of adenosine diphosphate. ${ }^{17}$

Controversies also surround appropriateness of linking short- and long-term thrombotic events in patients undergoing 
coronary invasive procedures with baseline values of platelet function tests and measures of antiplatelet resistance. Firstly, platelet function is not constant over time and prospective follow-up of the patients should encompass repetitive assessments of platelet inhibition parameters to clarify possible association between different measures of platelet inhibition and thrombotic events. Secondly, patients undergoing coronary interventions are exposed to many antithrombotic and other drugs interfering with COX-1 dependent action of aspirin and, therefore, it seems inappropriate to judge the presence or absence of aspirin resistance without excluding confounding factors. Thirdly, thrombotic events after coronary stenting or bypass grafting can depend strongly on the type of stents and surgical techniques used, but not on the efficiency of antiplatelet therapy. Finally, to what extent ethnicity and co-morbidities (eg, heart failure, diabetes, hypertension, and chronic inflammatory disorders) affect platelet function and underlie responsiveness to antiplatelets in those undergoing coronary interventions still remain to be determined. Unfortunately, these issues have not been sufficiently addressed in recent studies on aspirin resistance. ${ }^{8,18,19}$

In conclusion, aspirin and clopidogrel are currently widely used antiplatelet agents with relatively safe profiles and proven efficiency. Occurrence of thrombotic complications, despite mono or dual antiplatelet therapy, in most patients with stable cardiovascular disease and those undergoing coronary interventions has been linked to antiplatelet resistance. Multiple laboratory tests have been used to identify those who fail to respond fully to platelet-inhibiting effects of aspirin and clopidogrel and attempts have made to overcome the resistance by adding more powerful agents. It has become evident that intensive antiplatelet therapy, particularly with the novel thienopyridine agent prasugrel instead of clopidogrel, is justified in those at high risk of ischemic events. ${ }^{20}$ Nonetheless, it is not clear whether this or any other aggressive approach with powerful suppression of platelets is applicable in conditions associated with the risk of bleeding (eg, in diabetes, heart failure, or chronic inflammatory disorders).

More efforts are needed to standardize methods for defining laboratory responsiveness to old and new antiplatelet agents, to provide consensual definition of antiplatelet resistance, and to conduct prospective studies with serial platelet function assessment to ascertain links between laboratory and clinically defined antiplatelet resistance. Standardization should, first, imply selection of platelet function tests with minimal intra- and interassay variability (eg, MPV measurement), which can reliably identify 'true' laboratory defined resistance in research studies. Whether or not these tests can be recommended for clinical practice is subject to the results of future prospective studies, in which monitoring of platelet function should be combined with quantification of markers of inflammation, oxidative stress, and cardiovascular risk factors, and should be associated with a sufficient number of cardiovascular events.

\section{Disclosures}

The author discloses no conflicts of interest.

\section{References}

1. Antithrombotic Trialists' Collaboration. Collaborative meta-analysis of randomised trials of antiplatelet therapy for prevention of death, myocardial infarction, and stroke in high risk patients. $B M J$. 2002;324(7329):71-86.

2. Gasparyan AY, Watson T, Lip GY. The role of aspirin in cardiovascular prevention: implications of aspirin resistance. J Am Coll Cardiol. 2008;51(19):1829-1843.

3. Wang ZJ, Zhou YJ, Liu YY, et al. Impact of clopidogrel resistance on thrombotic events after percutaneous coronary intervention with drug-eluting stent. Thromb Res. 2009;124(1):46-51.

4. Snoep JD, Hovens MM, Eikenboom JC, van der Bom JG, Jukema JW, Huisman MV. Clopidogrel nonresponsiveness in patients undergoing percutaneous coronary intervention with stenting: a systematic review and meta-analysis. Am Heart J. 2007;154(2):221-231.

5. Schwartz KA, Schwartz DE, Barber K, Reeves M, De Franco AC. Noncompliance is the predominant cause of aspirin resistance in chronic coronary arterial disease patients. J Transl Med. 2008;6:46.

6. Cox D, Maree AO, Dooley M, Conroy R, Byrne MF, Fitzgerald DJ. Effect of enteric coating on antiplatelet activity of low-dose aspirin in healthy volunteers. Stroke. 2006;37(8):2153-2158.

7. Modica A, Karlsson F, Mooe T. Platelet aggregation and aspirin nonresponsiveness increase when an acute coronary syndrome is complicated by an infection. J Thromb Haemost. 2007;5(3):507-511.

8. Sharma RK, Reddy HK, Singh VN, Sharma R, Voelker DJ, Bhatt G. Aspirin and clopidogrel hyporesponsiveness in patients with coronary artery stenting. Vasc Health Risk Manag. 2009;5:965-972.

9. Cattaneo M. Laboratory detection of 'aspirin resistance': what test should we use (if any)? Eur Heart J. 2007;28(14):1673-1675.

10. Lordkipanidzé M, Pharand C, Schampaert E, Turgeon J, Palisaitis DA, Diodati JG. A comparison of six major platelet function tests to determine the prevalence of aspirin resistance in patients with stable coronary artery disease. Eur Heart J. 2007;28(14):1702-1708.

11. Lordkipanidzé M, Pharand C, Nguyen TA, Schampaert E, Palisaitis DA, Diodati JG. Comparison of four tests to assess inhibition of platelet function by clopidogrel in stable coronary artery disease patients. Eur Heart J. 2008;29(23):2877-2885.

12. Gasparyan A, Blann A, Watson T, Lip G. Platelet function in coronary artery disease: defining response to antiplatelets [abstract]. Atherosclerosis Suppl. 2008;9(1):209.

13. Sanioglu S, Tetik S, Sokullu O, et al. Aspirin resistance after CABG Thorac Cardiovasc Surg. 2009;57(5):281-285.

14. Aksu H, Ozer O, Unal H, et al. Significance of mean platelet volume on prognosis of patients with and without aspirin resistance in settings of non-ST-segment elevated acute coronary syndromes. Blood Coagul Fibrinolysis. 2009 Aug 27. [Epub ahead of print].

15. Erhart S, Beer JH, Reinhart WH. Influence of aspirin on platelet count and volume in humans. Acta Haematol. 1999;101(3):140-144.

16. Huczek Z, Filipiak KJ, Kochman J, et al. Baseline platelet size is increased in patients with acute coronary syndromes developing early stent thrombosis and predicts future residual platelet reactivity. A casecontrol study. Thromb Res. 2009 Sep 26. [Epub ahead of print]. 
17. Gum PA, Kottke-Marchant K, Welsh PA, White J, Topol EJ. A prospective, blinded determination of the natural history of aspirin resistance among stable patients with cardiovascular disease. J Am Coll Cardiol. 2003;41(6):961-965.

18. Ruef J, Kranzhöfer R. Coronary stent thrombosis related to aspirin resistance: what are the underlying mechanisms? J Interv Cardiol. 2006;19(6):507-509.

19. Zimmermann N, Gams E, Hohlfeld T. Aspirin in coronary artery bypass surgery: new aspects of and alternatives for an old antithrombotic agent. Eur J Cardiothorac Surg. 2008;34(1):93-108.
20. Wiviott SD, Braunwald E, McCabe CH, et al; TRITON-TIMI 38 Investigators. Intensive oral antiplatelet therapy for reduction of ischaemic events including stent thrombosis in patients with acute coronary syndromes treated with percutaneous coronary intervention and stenting in the TRITON-TIMI 38 trial: a subanalysis of a randomised trial. Lancet. 2008;371(9621):1353-1363.

\section{Publish your work in this journal}

Vascular Health and Risk Management is an international, peerreviewed journal of therapeutics and risk management, focusing on concise rapid reporting of clinical studies on the processes involved in the maintenance of vascular health; the monitoring, prevention and treatment of vascular disease and its sequelae; and the involvement of metabolic disorders, particularly diabetes. This journal is indexed on PubMed Central and MedLine. The manuscript management system is completely online and includes a very quick and fair peer-review system, which is all easy to use. Visit http://www.dovepress.com/ testimonials.php to read real quotes from published authors.

Submit your manuscript here: http://www.dovepress.com/vascular-health-and-risk-management-journal 